
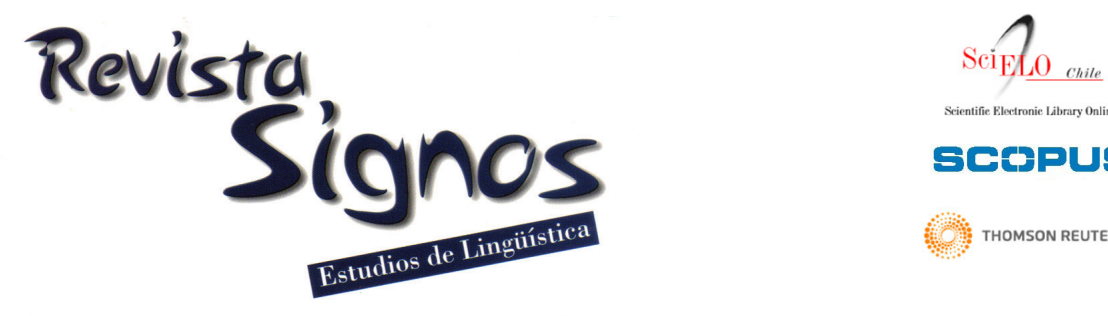

\title{
La Teoría de la Comunicabilidad: \\ Notas para una concepción integral de la comprensión de textos escritos*
}

\author{
The Communicability Theory: \\ Notes for an integral conception of written text comprehension
}

\author{
Giovanni Parodi \\ gparodi@ucv.cl \\ Pontificia Universidad Católica de Valparaíso \\ Chile
}

Recibido: 3-VII-20I0 / Aceptado: I8-I-20II

Resumen: En este artículo se exponen las bases teóricas de una concepción integral de la comprensión de textos escritos, denominada Teoría de la Comunicabilidad. Esta concepción teórica no constituye una propuesta totalmente nueva, sino que se avanza desde antecedentes teóricos y empíricos previos y se busca delimitarla de modo más definido, profundizar en ciertos aspectos y denominarla por primera vez de modo único. Dicha teoría se resume por medio de un principio fundante ('la acreditabilidad de lo comprendido') y tres supuestos centrales (el 'supuesto de la cognición situada', el 'supuesto de la interactividad' y el 'supuesto de la socioconstructividad'), los cuales a su vez se elaboran en diez supuestos más específicos.

Palabras Clave: Teoría de la Comunicabilidad, comprensión de textos escritos. 


\begin{abstract}
In this article the theoretical framework for a written comprehension theory, named the Communicability Theory, is presented.This theoretical conception is not a totally new one; it is based on previous theoretical reflections and empirical findings. Now it is further elaborated on, some aspects are gone into more detail, and it is named for the first time in a unique way. This theory is summed up by means of a founding principle (the 'accreditability of the comprehended') and three main assumptions (the 'situated cognition assumption', the 'interactivity assumption', and the 'socioconstructivity assumption'), which in turn are elaborated in ten more specific assumptions.
\end{abstract}

Key Words: Communicability Theory, written text comprehension.

\title{
INTRODUCCIÓN
}

Durante los últimos treinta años, en la Escuela Lingüística de Valparaíso se ha venido desarrollando, progresiva y acumulativamente, un cuerpo de conocimientos teórico-empíricos acerca de los procesos de comprensión de textos escritos siempre en torno a algunas ideas fundantes. Estos avances científicos se han materializado en la paulatina construcción de un marco teórico basado en indagaciones y hallazgos empíricos. Las ideas fundantes de esta fecunda línea de investigación están en las certeras e innovadoras contribuciones iniciales de nuestros maestros Marianne Peronard y Luis Gómez, a partir de cuyos preceptos hemos logrado establecer un programa de investigación que se ha ido consolidando a través del tiempo. Prueba de ello son las numerosas publicaciones de artículos, capítulos de libros y libros, los diversos proyectos de investigación, las propuestas de programas de desarrollo de estrategias y la construcción de instrumentos de evaluación, entre otros.

Asimismo, como parte del programa de investigación, se han ampliado y diversificado las líneas de estudio y los métodos empleados; de este modo, hemos avanzado desde el estudio de la comprensión en alumnos de educación básica o primaria a sujetos en educación superior (magíster y doctorado) y en el mundo profesional, desde la indagación de la incidencia de las superestructuras a los tipos de textos y a los géneros discursivos, desde el estudio del español como lengua materna al inglés como lengua extranjera, desde el foco exclusivo en comprensión a la conexión lectura-escritura, desde el foco en el texto y la identificación de la incidencia de variables exclusivamente lingüísticas al foco en el lector y sus procesos metacomprensivos, desde la lectura en papel a la lectura en pantalla de computadora, desde los textos predominantemente verbales a los multimodales y disciplinares, desde las inferencias off-line a la investigación de inferencias on-line y con apoyos computacionales y -más recientementedesde la investigación no-experimental a la experimental. Desde estos hallazgos empíricos, hemos desarrollado diversos programas para el desarrollo de estrategias tanto de la lectura como de la escritura para ser implementados en diversos grados educacionales, con apoyo en soporte papel como con menor o mayor dependencia de soporte multimedia, tal como son el Programa LyC y el Programa LECTES (www.lectes.cl).

Este rico y diverso escenario invita a la proposición integradora de un marco conceptual. Precisamente, en este artículo, exponemos una teoría de la comprensión de textos escritos que denominamos: Teoría de la Comunicabilidad. En este artículo buscamos delimitarla con mayor precisión, extenderla y denominarla por primera vez de modo único; para ello, establecemos un principio fundamental y un conjunto de supuestos, tanto generales como específicos.

Así, este trabajo no debe entenderse como acabado ni definitivo, sino -como es de esperarse de toda propuesta de esta índole- en permanente construcción y desarrollo acumulativo.

\section{El hombre y el lenguaje}

No parece posible iniciar un artículo como el proyectado sin comentar nuestra posición en relación al hombre y al lenguaje. Tal como ya hemos declarado en otros trabajos, nuestra perspectiva epistemológica es de naturaleza socioconstructivista y de corte psicosociolingüístico. Estos postulados implican que concebimos al ser humano como poseedor de una facultad innata y particular del lenguaje, la cual le permite co-construirse como 
persona por medio de su participación activa en su sociedad y de autogestionar su propia construcción de conocimientos en la interacción psicosociolingüística con los miembros de la comunidad en la que se inserta. Esta visión singular del ser humano y su lenguaje arranca de una visión dualista monista:

"El dualismo de la persona humana cubre múltiples dimensiones que se entrecruzan y complementan. La persona humana es genética y cultura; cerebro y yo; individuo y sociedad; inmanencia y trascendencia; tradición e innovación; persistencia y cambio; todas ellas, entrelazadas de manera indisoluble, configuran una unidad sustancial” (Peronard \& Gómez, I 985: I).

Desde esta conceptualización, conciencia del yo y facultad del lenguaje se constituyen en rasgos prototípicos del ser humano. Reiteramos así que esta facultad del lenguaje es de naturaleza innata a la especie humana y se constituye en un potencial fundamental para la construcción de diversos sistemas de significado. No obstante ello, esta facultad no es postulada como un componente pre-dado, a modo de universales lingüísticos, sino como una potencia para la elaboración paulatina de diversos sistemas de semantización, elaborados socioconstructivamente a través de procesos ontogenéticos. Ciertamente, nada de esto sería posible $\sin$ una comunidad discursiva que apoye, estimule y ofrezca a cada sujeto diversas y ricas oportunidades de desarrollo. En este contexto, es innegable que el ser humano y su conocimiento no se construyen a sí mismos en el solipsismo de sus capacidades innatas ni se puede prescindir de la sociedad para el total desarrollo de todas sus potencialidades.

\section{La Teoría de la Comunicabilidad}

Lo dicho anteriormente es congruente con nuestra concepción del proceso de comprensión de textos escritos como una actividad controlada por el propio lector, basada en sus conocimientos previos y de acuerdo con los contextos sociales y culturales en que ella se produce.Así, nuestra teoría de la comprensión de textos escritos se ha ido enriqueciendo progresivamente durante los últimos años (Peronard \& Gómez, 1985; Parodi, 1992, 1993, 2003, 2005, 2007a, 2007b, 20I0a, 20I0b, 20Ila, $201 \mathrm{lb}$; Peronard, Gómez, Parodi \& Núñez, 1998; Peronard, Velásquez, Crespo \& Viramonte, 2002; Peronard, 2005; Ibáñez, 2007a, 2007b, 2008; Parodi, Peronard \& Ibáñez, 2010). Si bien esta concepción no ha variado en lo esencial, sí hemos profundizado y expandido ciertos aspectos teóricos y explorado empíricamente otros por medio de técnicas variadas, desplazándonos así hacia nuevos horizontes como son, por ejemplo, los géneros disciplinares y sus relaciones textuales prototípicas y su incidencia en el procesamiento psicolingüístico.

La comprensión de textos escritos es así postulada fundamentalmente como un macroproceso multidimensional en el que intervienen múltiples factores de tipo psico-socio-bio-lingüístico y en cuyo núcleo convergen diversos tipos de conocimientos entre otros- declarativos y procedimentales. Por ello justamente se postula su carácter multidimensional, pues ella no se deja explicar por medio de una sola dimensión o factor y se hace necesario identificar diversos planos y dimensiones intrínsecamente vinculadas. De modo más explícito:

“[...] nuestra perspectiva es psicosociolingüística. Psicológica, por cuanto consideramos la comprensión como producto de procesos mentales estratégicos; social por cuanto consideramos el contexto cultural y situacional que determina la diversidad de textos; lingüística, puesto que aquello que pretendemos que los lectores enfrenten son actos de comunicación mediante la modalidad escrita de la lengua, esto es, textos escritos" (Parodi et al., 2010: II-12).

Entre el párrafo anterior y esta última cita queda pendiente mayor explicitud acerca de las bases biológicas del procesamiento de la lengua escrita. No cabe duda de que en la actualidad la investigación experimental con tecnologías de diversa índole está aportando cada vez más detalles, aunque en muchos casos aún preliminares, que nos permiten aproximarnos a comprender inicialmente ciertos fundamentos de los sustratos biológicos de algunos de los procesos implicados en la comprensión de textos escritos. Que en el cerebro acontece gran parte de los procesos de comprensión de textos escritos es un hecho irrefutable, pero nuestra concepción del proceso mismo va más allá de lo exclusivamente físico. El debate contemporáneo no ha logrado aún, científicamente y de modo certero, dilucidar del todo cuestiones como los sentimientos, la conciencia del yo, la mente, la motivación y el inconsciente, por mencionar solo algunos de los temas centrales. Es más, existe abundante literatura en que se discute si efectivamente vale la pena hablar de semejantes cuestiones en términos científicos (Penrose, 1996; Solms \& Turnbull, 2004; Koch, 2004; Damasio, 2006, 2010). Esto no quiere decir que estemos postulando una suerte de animismo, misticismo radical o alma inmortal (Penrose, 1996; 
Damasio, 20l0), como sí se afirma, desde una perspectiva exageradamente antifisicalista, según la cual existiría un eje extremo en la concepción del pensamiento consciente en que se postula que:

"El conocimiento no puede explicarse en términos físicos, computacionales o cualesquiera otros términos" (Penrose, 1996: 26).

Mente y cerebro constituyen una singular sinergia, pero no son exactamente lo mismo y puede ser que la pregunta no sea exactamente dónde reside la mente, sino cómo interactúan y uno determina al otro (Searle, 2004). Esto implica que, aunque aceptamos el innegable rol del cerebro en los procesos de comprensión, también adherimos a una visión mentalista, según la cual, la mente co-participa fundamentalmente en el procesamiento del lenguaje escrito.

Ahora bien, a lo largo de los desarrollos en el marco de nuestra concepción de la comprensión del discurso escrito, hemos puesto atención al estudio y revisión de diversas teorías y/o modelos de comprensión (Parodi, 2003, 2005) con el doble objetivo de conocer el estado del arte así como de rescatar aportes significativos. Este recorrido revela que no pretendemos ser ajenos a los avances teóricos ni empíricos provenientes de otras latitudes; muy por el contrario, es evidente que parte de nuestras propias concepciones se cimientan en importantes núcleos teóricos elaborados dentro de esas otras teorías, aunque no siempre en el mismo tenor ni bajo los mismos supuestos ontológicos y epistemológicos. Asimismo, partiendo del supuesto de que es posible constatar cierto consenso en torno a algunos constructos teórico-empíricos, nuestra intención en este artículo es destacar ciertas particularidades de la Teoría de la Comunicabilidad (TC) y no establecer explícitamente vinculaciones con otras propuestas, tal como ya hemos hecho en diversos trabajos previos (Parodi, 2003, 2005, 2007).

Tal como ya hemos insistido, la TC no constituye una propuesta conceptual totalmente nueva, sino que bajo este nombre buscamos consolidar la postura que se ha venido construyendo paulatinamente al interior de la Escuela Lingüística de Valparaíso (ELV). Precisamente, al aunar nuestros trabajos en torno a la TC se ofrece un panorama de conjunto que esperamos dé cuenta de la postura teórica que defendemos. En esta teoría de la comprensión de textos escritos existe un principio fundamental que dice relación con que el lector 'comunique o acredite lo comprendido', pues solo así será posible saber para sí mismo y para su audiencia si efectivamente comprendió o no. Ello requiere de un proceso de indagación consciente y de autoexplicación en que el lector logre saber qué ha comprendido y alcance la plenitud en la construcción de nuevos conocimientos.

Ahora bien, al referirnos a la TC como una teoría no somos ajenos al debate que existe entre teoría y modelo y al uso frecuente que de estos términos se hace como si fueran sinónimos 0 al menos intercambiables en ciertos contextos. Como se sabe, usualmente se dice que una teoría explica un determinado fenómeno y que un modelo describe o da cuenta de las partes o componentes de la realidad a la que se refiere dicha teoría. En la práctica, en algunos campos disciplinares, esta distinción no se aplica regular y sistemáticamente, al menos no en estricto rigor, tal y como se comprueba en la abundante literatura acerca de teorías y modelos de comprensión (Kintsch, 1998; Parodi, 2003, 2005, 2007a; Graesser, 2007; McNamara \& Magliano, 2009). En nuestro caso, hemos optado por el término teoría para nombrar a la TC, pues creemos que la investigación desde esta perspectiva se encuentra suficientemente madura para ofrecer una propuesta acerca de la comprensión de textos escritos, una que pueda dar cuenta del procesamiento del texto escrito, entregándonos una mirada más integral y a la vez integradora.

Así, en la TC establecemos un principio, la 'acreditabilidad de lo comprendido', y tres supuestos centrales distintivos: a) el 'supuesto de la cognición situada', b) el 'supuesto de la interactividad', y c) el 'supuesto de la socioconstructividad'.

\section{I. El principio de la TC: La acreditabilidad de lo comprendido}

Bajo el principio de la 'acreditabilidad de lo comprendido' -en lo nuclear- se establece que todo lector debe ser capaz de, sobre la base de los supuestos generales a describir más adelante, dar cuenta de lo leído y comunicarlo verbalmente, toda vez que haya construido una representación coherente de los significados del texto, a la luz de sus conocimientos previos, de sus estrategias, de su capacidad inferencial y de sus objetivos de lectura. De este modo, se constituye en requisito indispensable la verbalización o expresividad, esto es, la producción oral o escrita como medio de acreditabilidad del contenido del texto comprendido. Este principio irrenunciable de la TC impone un circuito de comunicación en que el lector debe transmitir, por 
medio de la lengua escrita $\circ$ de la lengua oral, la construcción que ha realizado de los significados del texto. Desde este principio, lectura y escritura y lectura y oralidad se encuentran intrínsecamente relacionadas, porque comprender -desde esta perspectiva-implica escribir o decir lo comprendido (incluso a uno mismo); todo ello con el propósito de que la comunicabilidad de lo leído emerja y revele la construcción que el lector ha elaborado en su mente y en su cerebro. Esto implica que acreditar lo comprendido exija un cierto dominio de la producción ya sea oral o escrita, pues es requisito del principio la verbalización de lo comprendido. Por ello, el mero reconocimiento o identificación de respuestas posibles o ideas ya verbalizadas por otros no necesariamente se hace parte de este principio. Así, la elaboración propia de una expresión verbal que acredite lo comprendido se constituye como fundamental para asegurar efectivamente que se ha llegado a construir una representación coherente de los significados del texto. No obstante lo anterior, eventualmente, también es factible (por ejemplo, en niños) que la acreditabilidad de lo comprendido se manifieste 0 realice por medio de otros sistemas semióticos, tales como una secuencia de dibujos o mediante la relación intersemiótica entre más de un sistema semiótico: por ejemplo, verbal y gráfico.

En este escenario, la comunicabilidad de lo leído constituye la culminación y al mismo tiempo el principio fundante de la TC y ciertamente se postula como el requisito imprescindible: si no se comunica lo leído a otros lectores u oyentes o a sí mismo, la comprensión plena del texto no se ha alcanzado. Esto quiere decir que no basta con construir una representación interna de lo leído, sino que esa representación debe ser compartida y expresada. De hecho, esa construcción de una representación de lo leído muchas veces se termina de ajustar en el acto mismo de comunicabilidad. Esto es, al enfrentarse a la tarea de decirse a uno mismo u a otros el contenido del texto leído es exactamente cuando reflexionamos de si efectivamente hemos logrado comprender el texto fuente, a la luz del objetivo de lectura que se había establecido. Este acto de acreditabilidad se constituye así en revisión de la representación elaborada y en una eventual re-representación o construcción de una nueva representación, que posiblemente ofrezca lugar a una comprensión más plena.

La comunicabilidad de lo leído no debe entenderse como un mecanismo de evaluación de la comprensión, sino como una actividad intrínseca del proceso de comprensión. Ser capaz de decirse a uno mismo de qué trata el texto leído o de comunicar a otros y socializar la construcción realizada a partir del texto constituye, desde la TC, un eslabón en el proceso de construcción de una representación coherente con los significados del texto, en el marco de ciertos objetivos de lectura. Evaluar la comprensión puede efectuarse mediante muy diversos instrumentos $y$ no necesariamente implica comunicar verbalmente lo leído, pues -en algunos casos- la evaluación de la lectura puede llevarse a cabo mediante el reconocimiento de datos o la identificación de información específica y no de una verbalización propiamente tal. Pero, si el lector ha comunicado y acreditado lo comprendido, es factible que acierte en esas tareas de reconocimiento de información como medio de evaluación de su lectura.

\subsection{Los supuestos generales}

En cuanto a los tres supuestos generales, por una parte, el 'supuesto de la cognición situada' implica aceptar que la comprensión no acontece in vacuo, sino muy por el contrario en entornos ecológicos y en donde los procesos discursivos están influidos por los contextos sociohistóricos. En este sentido, la cognición no opera en abstracto y los lectores construyen sus representaciones a partir de textos originales e influidos por sus historias de vida y sus conocimientos, construidos a partir de fuentes culturales y sociales diversas. Es así como el establecimiento de la coherencia, los procesos de inferencia, los objetivos de lectura y los conocimientos previos son algunos de los ejes centrales de este supuesto, pero siempre en contextos determinados históricamente. De hecho, el principio de la comunicabilidad de lo leído justamente se vincula directamente a una cognición de tipo distribuida, ya que se comparte y se puede llegar a consensuar lo comprendido. Por otra parte, el 'supuesto de la interactividad' instala como eje fundamental la vinculación entre diversos procesos internos del lector, el texto y el contexto. Ya sea que se trate de interrelacionar información en diversos niveles jerárquicos del texto, de construir una representación coherente a nivel local y global de modo vinculante, de procesar la información en construcción -inicialmente de naturaleza lingüísticaen ciclos de modo lineal o en paralelo. Y, en tercer lugar, desde el 'supuesto de la socioconstructividad' se postula el progresivo y paulatino desarrollo del sujeto en cuanto lector desde sus bases biológicas en entornos sociales particulares, mediante el ejercicio gradual de la toma de conciencia del yo 
y de la automatización de procesos, pero a la vez del manejo del control consciente a través del cual se desarrollan estrategias de lectura con el fin de construir el significado intentado en el texto.

Estos supuestos centrales inspiran y dan sustento a nuestra concepción psicosociobiolingüística de la comprensión en la cual el lector, el texto y el contexto son elementos centrales de la TC y la aproximación es decididamente discursiva y cognitiva. En lo que sigue, exponemos diez supuestos específicos que se desprenden de estos tres generales.

\subsection{Tres supuestos generales y diez supuestos específicos}

Tal como se dijo más arriba, en la Tabla I presentamos los tres supuestos generales y los diez supuestos específicos de la TC. Estos últimos no se muestran de modo jerárquico, sino solo agrupados en torno al supuesto general del cual se desprenden.

A continuación, entregamos un breve comentario acerca de cada uno de estos supuestos específicos. Vale la pena insistir en que a pesar de abordarse, por razones metodológicas, de forma separada, los procesos subyacentes a estos supuestos están íntimamente ligados y muchas veces se superponen de modo indisoluble.

\subsection{Los supuestos de la TC}

I) Búsqueda de la coherencia discursiva: La construcción de la coherencia a partir de un texto escrito es una condición fundamental para la construcción de los significados del texto. Esta puede emerger desde la información superficial del texto, es decir, desde de ciertas marcas explícitas -señaladas lingüísticamente y otras no marcadasy también del conocimiento previo del lector, acorde a sus objetivos. Desde esta concepción, la naturaleza de la información textual es de carácter multisemiótico, vale decir, se constituye a partir de diversos sistemas semióticos y no exclusivamente del verbal, que ha sido el más estudiado clásicamente. Este proceso de búsqueda 0 indagación se caracteriza por ser una actividad intencionada por parte del lector, en la cual debe poner su empeño y sus habilidades de diverso tipo. Por supuesto que sus conocimientos previos son requisito imprescindible y no basta solo la información textual y las marcas relacionales y el léxico. Desde la TC, este supuesto se constituye en el primero de los específicos, pues si el lector no busca el establecimiento de la

Tabla I. Supuestos centrales y específicos de la TC.

\section{I) El supuesto de la cognición situada}

I. Búsqueda de la coherencia discursiva

2. Centralidad de los procesos inferenciales

3. Orientación del proceso lector de acuerdo a objetivos del lector y objetivos funcionales

4. Dependencia fundamental de los conocimientos previos

\section{II) El supuesto de la interactividad}

5. Secuencialidad de procesamientos en paralelo a partir de diversas fuentes de información

6. Interactividad entre el lector, el texto y el contexto

7. Diversidad de niveles y formatos de representación

III) El supuesto de la socioconstructividad

8. Proceso progresivo de toma de conciencia y control

9. Desarrollo ontogenético, progresivo y permanente, de estrategias, según tareas, géneros discursivos, temáticas, etc.

10. Complementariedad entre disposiciones innatas y procesos evolutivos 
coherencia no es posible intentar la comprensión del texto. En la actualidad aún no existe un consenso definitivo respecto de la definición de coherencia y no resulta para muchos un término unívoco. Incluso para algunos es sinónimo de cohesión. En el marco de la TC, la coherencia se distingue de la cohesión y no siempre se fundamenta en ella. La coherencia es un proceso de orden psicolingüístico en el que se construyen los significados del texto tanto a nivel local como global. Puede entenderse como proceso y como producto, pues permite llegar a la construcción de una representación del texto en la mente del lector y también es parte de los mecanismos cognitivos relacionales que llegan a producir esa representación. En este sentido, la cohesión es textual, mientras que la coherencia es, en gran medida, de orden mental. Para comprender un texto escrito, todo lector debe ir en pos de su construcción.

2) Centralidad de los procesos inferenciales: Existe amplio consenso acerca de la relevancia de los procesos inferenciales en la comprensión de textos escritos y de su rol primordial en el procesamiento del discurso. Justamente por ello, algunos investigadores han declarado que ellas constituyen el corazón de los procesos de comprensión de textos. Por una parte, la naturaleza de la mente y del razonamiento humano muestra que el modo de procesar la información procede estableciendo conexiones y proyectando más allá de lo evidente y observable, siendo las inferencias las que posibilitan este tipo de vinculaciones. Por otra parte, la naturaleza del texto escrito, como unidad en parte opaca y no totalmente transparente y explícita, obliga al lector a la construcción de una representación mental de los significados intentados por parte del escritor, completando los espacios informacionales vacíos, conectando lo aparentemente no vinculado, rescatando los implícitos existentes y aportando desde su conocimiento previo información de diversa índole. Por ello, nuestra concepción de las inferencias es doble: constituyen procedimientos que andamian la arquitectura de lo comprendido y también constituyen las representaciones de esa nueva información no explicitada en el texto mismo. De cualquier modo que se miren, son los mecanismos fundamentales que todo lector debe aprender a poner en práctica y a desarrollar progresivamente -entre otros- ante nuevas palabras, nuevos textos, nuevas tramas textuales, nuevas temáticas y nuevos géneros discursivos. Por ello, las inferencias se conciben como altamente dinámicas y adaptativas y se les asigna una función vital en el proceso de comprensión de textos escritos. Definitivamente no son de naturaleza innata y se deben desarrollar a lo largo de toda la vida de un lector. Su variedad es amplia y sus clasificaciones han sido objeto de diversas investigaciones, aunque su naturaleza, funcionamiento y modos de desarrollarlas son aún materia en franca investigación y encierran encrucijadas tremendas. Se puede lograr una relativa competencia en su aplicación; no obstante, siempre habrá nuevas situaciones de lectura que impondrán nuevos desafíos y posibles nuevas inferencias que realizar. Esta centralidad que les otorgamos en la comprensión hace que se constituyan en mecanismos imprescindibles para la construcción de la coherencia discursiva, supuesto anteriormente enunciado más arriba.

3) Orientación del proceso lector de acuerdo a objetivos del lector y objetivos funcionales: A pesar de que no constituye una novedad considerar los objetivos de lectura por parte del lector dentro de una teoría de la comprensión, es innegable que ellos no han recibido la misma atención que otros aspectos como, por ejemplo, las inferencias o las estrategias. De hecho, nuestras propias investigaciones solo recientemente los han abordado de modo frontal y lo hemos hecho partiendo de una distinción entre: objetivos de lectura y objetivos funcionales. Así, los objetivos de lectura corresponden de modo único al lector y son de naturaleza interna o intrínseca, suelen ser de naturaleza consciente y dicen relación con el propósito del acto de leer o con el fin que persigue con esa lectura. La mayoría de los lectores saben, con mayor o menor grado de conciencia, si enfrentan un texto para aprender un determinado contenido o procedimiento, buscar una definición particular, memorizar cierta información o pasar un tiempo libre. En virtud de esta decisión del lector, pondrá en acción estrategias diversas para cumplir con ese objetivo. Por su parte, los objetivos funcionales provienen del contexto institucional y externo al lector, pues son impuestos o propuestos por organismos o personas en algún entorno formal de lectura. Este segundo tipo de objetivos busca guiar u orientar la comprensión del lector desde el punto de vista del sistema en que este se encuentre inmerso según una determinada tarea o demanda específica y, en función de ello será evaluado, calificado o juzgado; por ello, es fundamental que el lector sea capaz de distinguir entre los propios objetivos y los externos y logre enfocar su lectura según sea el caso. Es factible que el lector, sin necesariamente contar con objetivos de lectura propios o aún teniéndolos, haga suyos los funcionales o también es posible que ambos lleguen a coincidir. También puede acontecer que en determinadas situaciones de lectura, no 
existan objetivos funcionales y el lector solo esté guiado por sus propios objetivos o propósitos de lectura, de los cuales el grado de conciencia puede variar.

4) Dependencia fundamental de los conocimientos previos: La comprensión del texto escrito es un proceso que se articula entre el texto escrito y el lector, en un contexto determinado. En este escenario, el lector es un actor central tanto para ejecutar voluntaria y activamente el acto de leer como para guiar y controlar el procesamiento del contenido en elaboración. Todo este proceso descansa, de modo único, en los conocimientos del lector y en su voluntad para activarlos y hacerlos participar en la construcción de los significados que se están elaborando a partir de la información proveniente del texto. Existe una amplia y diversa gama de saberes que todo lector debe construir a lo largo de su vida y que se espera ponga en juego en la construcción de una nueva representación mental a partir de la información textual. Entre otros, se puede señalar el conocimiento general del mundo, de temas generales y específicos, del sistema de la lengua, de los diversos géneros del discurso, de las estrategias de lectura, de los objetivos posibles, etc. Todos ellos están almacenados, con mayor o menor grado de accesibilidad, en los diversos sistemas mnemónicos que se han logrado identificar y desde los cuales son activados y recuperados para aportar a la comprensión en curso. Estos conocimientos se han construido situadamente, esto es, se han elaborado a partir de experiencias individuales y grupales en contextos sociohistóricos particulares; por ello, no todo lector dispone exactamente de los mismos conocimientos previos y, justamente por ello, es factible que se construyan representaciones mentales levemente diferentes a partir de un mismo texto fuente.

5) Secuencialidad de procesamientos en paralelo a partir de diversas fuentes de información: Durante los últimos 30 años se ha debatido acerca de si la comprensión del texto responde, por un lado, a un proceso únicamente lineal y jerárquico o con diversos procesos en paralelo y, por otro, si está guiada por los datos del texto o exclusivamente por los conocimientos previos del lector. Estas posturas excluyentes y a veces radicales se han ido desplazando de uno a otro extremo y, en los últimos tiempos, se han alcanzado ciertos consensos. Desde la TC, declaramos que la comprensión acontece basada en procesamientos de diversa naturaleza y que se ejecutan en diversos ciclos desde fuentes diversas de información que se van integrando paulatinamente. Así, desde la TC, postulamos que el lector es capaz de llevar a cabo procesos de modo simultáneo, según sea el tipo de información y el momento de lectura, alternando la información del texto y sus conocimientos previos y buscando un equilibrio o complementariedad entre ambos. Nuestras investigaciones han revelado que a veces los lectores se dejan influir inicialmente en demasía por sus conocimientos previos, pero que progresivamente se tiende a un equilibrio con la información del texto y la representación que el lector va construyendo logra capturar el sentido del texto de modo más certero.

6) Interactividad entre el lector, el texto y el contexto: Esta interactividad entre lector, texto y contexto, en el marco de la TC, se concibe en un doble sentido. Por una parte, dice relación con la interactividad entre los procesos que acontecen al interior del lector (activación de conocimientos previos, construcción de representaciones, inferencias, etc.); por otra, se refiere a que lector, texto y contexto comparten un espacio y un tiempo y se influyen mutuamente en la construcción de una representación mental del texto leído. Por esto mismo, no prima necesariamente un componente sobre otro. Por ejemplo, si este supuesto estuviera inspirado en principios radicales desde una lingüística social, el lector y sus procesos mentales serían irreconciliables con el texto y privilegiaríamos el contexto social. Esta ciertamente no es la visión que defendemos, ya que se polariza y radicaliza. Nuestros principios socioconstructivistas de corte discursivo cognitivista imponen una interactividad equilibrada. En este marco, los procesos interactivos ocurren al interior del individuo lector, pero también en su relación con y a partir del texto, con los otros sujetos lectores u oyentes y con el contexto.

7) Diversidad de niveles y formatos de representación: A pesar de que se habla de supuestos no-controversiales en la literatura de los últimos años, no existe un consenso definitivo acerca de cuántos ni cuáles serían exactamente los niveles de representación que el lector construiría durante la lectura de un texto. Tampoco se ha llegado a un acuerdo definitivo respecto de los formatos de estas representaciones. En el contexto de la TC, aceptamos que existen representaciones de tipo lingüístico y proposicional, pero que también -dada la naturaleza multisemiótica de muchos textos- es innegable que deben existir otros tipos de representaciones de corte gráfico-visual y matemático. No obstante 
ello, es también importante declarar que existe una jerarquía de procesamiento y que los menos apegados al texto deberán ser recodificados en otros tipos de representaciones de corte más semántico. Por ello, las proposiciones, aunque ampliamente aceptadas pero no definitivamente comprobadas empíricamente, no son el único formato en que codificamos la información que se procesa a partir del texto escrito. Desde la TC, postulamos que existen representaciones de tipo lingüístico, proposicional y de otras menos apegadas al código lingüístico y de orden más semántico; también consignamos que estas representaciones se articulan en ciclos de procesamiento que implican niveles más básicos y otros más complejos e inclusivos los previos.

8) Proceso progresivo de toma de conciencia y control: Tal como se apuntaba más arriba, el proceso lector debe ser guiado y controlado por el lector. Esto implica un paulatino desarrollo de la capacidad metacognitiva, a través de la cual el sujeto se va haciendo consciente del conocimiento disponible acerca de diversos aspectos y también va aprendiendo a ejercer el control de la situación de lectura. Este mecanismo de conciencia de la comprensión textual y sus diversos procesos y subprocesos en relación, por ejemplo, al texto escrito, al lector mismo, al conocimiento previo, a las estrategias lectoras, entre otros, se desarrolla contextualmente y en colaboración con otros lectores. Así, la metacomprensión y su correspondiente desarrollo ontogenético son parte relevante del macroproceso de comprensión. Tanto el conocimiento de las habilidades lectoras como de las de regulación del proceso deben llegar a ser contenidos de la conciencia del lector (cuando sean necesarios), del mismo modo que muchos de sus mecanismos deben funcionar automáticamente mientras así logren su objetivo. En este marco, el mecanismo de control de la comprensión implica un estado de alerta del lector que le permita detectar errores, ya sea referente a la generación de hipótesis y sus correspondientes verificaciones; así como a su integración junto a los significados en construcción en una globalidad coherente e integradora. Se trata de un tipo de actividad metacognitiva y metalingüística de autoevaluación constante que el lector realiza desde su propio proceso de interpretación y sobre el cual se valida la construcción de sentidos a partir de la información recibida. Ello le permite al lector continuar la lectura del texto o, en caso contrario, adoptar alguna estrategia para, por ejemplo, volver hacia atrás en el texto y releer cierta parte, continuar la lectura en espera de obtener mayor comprensión del tema en cuestión o, incluso, abandonar la lectura.

9) Desarrollo ontogenético, progresivo y permanente, de estrategias, según tareas, géneros discursivos, temáticas, etc.: Desde el supuesto general socioconstructivista de la TC, el desarrollo de estrategias de lectura acorde a las demandas diversas es un asunto que no se declara como acabado en ningún momento del proceso evolutivo de cada ser humano. Por ello, es primordial consignar que postulamos que todo sujeto podrá a lo largo de toda su vida poner en ejecución, incrementar y mejorar sus estrategias de lectura comprensiva al enfrentar nuevos textos, por ejemplo con temáticas y organizaciones discursivas originales. Este supuesto habilita a todo lector para poder enfrentar en igualdad de condiciones la comprensión de uno u otro texto en contextos emergentes y constantemente diversos, gracias a sus disposiciones innatas y sus habilidades de adaptación, mediante la interacción social y el desarrollo ontogenético. Desde este supuesto no existen limitaciones de ningún tipo para que todo lector $y$ en grados crecientes de experticia logre disponer y aplicar nuevas y más eficientes estrategias de lectura en contextos nóveles. En este sentido, este supuesto se sustenta en el progresivo y permanente, pero gradual y acumulativo, desarrollo de estrategias para el procesamiento del texto escrito a partir de las diversas organizaciones discursivas, géneros, objetivos, tareas, temáticas, etc.

10) Complementariedad entre disposiciones innatas y procesos evolutivos: Aprender a comprender textos escritos exige ciertos requerimientos biológicos generales y filogenéticamente predados en la especie humana, aunque no específicos pues el manejo de la lengua escrita es un desarrollo instrumental no genéticamente codificado de modo determinado en la especie y, por lo tanto, debe ser desarrollado ontogenéticamente por cada sujeto lector. De la distinción entre disposiciones innatas generales y procesos evolutivos particulares insistimos en que no existe una dotación genética específica para la lengua escrita, pero sí procesos básicos generales que posibilitan su desarrollo. Esto es, existen disposiciones cognitivas generales que en conjunto con procesos de enseñanza/aprendizaje y el desarrollo paulatino de estrategias eficientes en contextos culturales determinados posibilitan el logro de una habilidad como es la lectura comprensiva. 
Así, los denominados procesos básicos: percepción, memoria y atención se constituyen en eslabones fundamentales para la lectura. Es innegable que los sistemas de memoria, por ejemplo, constituyen un sustrato fundamental, tanto para el almacenamiento de los conocimientos previos de diversa índole así como para el efectivo procesamiento de la información en construcción durante y con posterioridad a la lectura; también para la permanencia de los conocimientos construidos a partir de la lectura y su uso posterior en otras instancias diversas.

\section{3. ¿Qué significa comprender un texto escrito a la luz de la TC?}

Tal como ya hemos señalado en este artículo, y a la luz de los supuestos declarados y esbozados brevemente más arriba, definimos la comprensión de un texto escrito, de modo sucinto, como un macroproceso constructivo e intencionado a través del cual el lector construye una interpretación de los significados intentados por un escritor, basándose tanto en la información del texto escrito como en sus conocimientos previos, de acuerdo a un objetivo de lectura y a las posibles demandas del medio social. Idealmente, este macroproceso se plasma a través de diversos procesos específicos (muchos de los cuales ocurren en paralelo) en una representación mental coherente en la memoria del lector, construida sobre la base de diversos tipos de procesos inferenciales. Desde esta perspectiva, las inferencias pueden generarse aleatoria y parsimoniosamente de modo que sobrepasen al proceso mismo de lectura y proyecten un procesamiento que pueda permanecer en ejecución con posterioridad al acto de lectura mismo.

Al respecto, Parodi et al. (20I0: I5I) señalan que:

"un lector crítico y reflexivo, que busca aprender a partir de lo que lee, debe evaluar el contenido del texto e identificar sus propias creencias y posturas $y$ distinguirlas de las del autor del texto".

Ahora bien, desde el marco de la TC y el principio de la 'acreditabilidad de lo comprendido', se ha señalado la relevancia de la verbalización de lo comprendido como requisito ineludible en que el lector debe dar cuenta de lo que ha leído. Con el fin de graficar y visualizar este proceso de construcción de significados a partir del texto y de la acreditabilidad de lo comprendido, presentamos a continuación la Figura I, por medio de la cual se da cuenta del 'circuito de comunicabilidad de lo leído'.

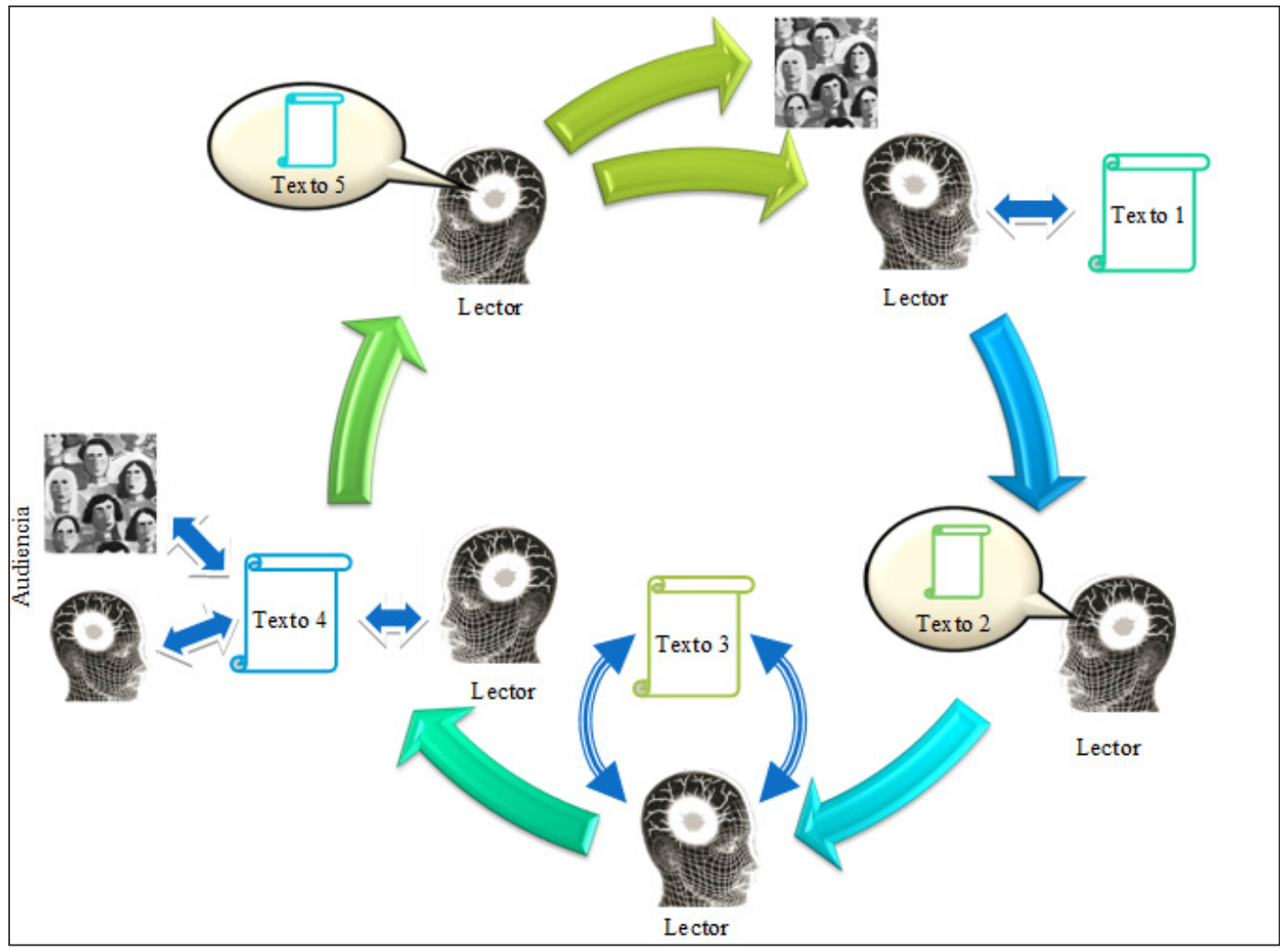

Figura I. Circuito de la comunicabilidad de lo leído. 
Como se muestra en la Figura I, desde la TC es posible establecer la existencia de -al menos- cinco textos identificables dentro de este circuito. En este circuito se plasman tanto el principio básico así como los tres supuestos centrales, aunque no se identifican de modo directo algunos de los supuestos específicos. El circuito se inicia a partir de Texto $\mathrm{I}$, que es el texto en formato papel o en soporte digital, visualizado en pantalla de computador u otro medio o sistema. Este texto inicial constituye la fuente de información que gatilla o sirve de primer activador de la lectura. A partir de la interacción del lector con este primer texto se construye la primera representación mental de lo leído, esto es, el llamado Texto 2. Si esta construcción de los significados del texto inicial por parte del lector alcanza un procesamiento profundo y supera una copia literal de la información superficial del texto, se llegaría al nivel superior de representación que se conoce técnicamente como modelo de situación.

Desde la mirada de un lector no experto, la primera lectura de un texto podría no llegar a constituir una representación completa. Ello implicaría que el lector debería realizar una o más lecturas antes de efectivamente llegar a un siguiente paso en el circuito. En este proceso justamente se postula el Texto 3, que da cuenta del diálogo del lector consigo mismo, por medio de la interrogación a sí mismo y su capacidad reflexiva y metacognitiva.

Desde una mirada idealizada, una vez que este acto de internalización alcanza una fase de cierta estabilización, se procede al Texto 4, que es efectivamente 'lo comunicado'. Este es un texto verbalizado y que ciertamente puede no coincidir por completo con el Texto 3, pues -al comunicarloel conocimiento elaborado a partir de la lectura se transforma, se ajusta y se revisa. Es decir, deja de ser una representación más bien personal para presentarse como un texto expresado o comunicado a otro u otros (Audiencia). Este nuevo texto en proceso de construcción se somete a nueva revisión por medio de la negociación de significados con otros lectores o solo oyentes. Así, mediante este proceso recursivo y en múltiples ciclos, se articula una nueva representación mental que denominamos Texto 5, en el cual el lector (re) elabora sus textos previos e incorpora en uno nuevo las diversas versiones y revisiones que se muestran en el circuito.

De este modo, el lector que alcanza un Texto 5, se espera no solo haya conseguido una representación coherente y socializada sino que desde esta pueda llegar a la construcción de aprendizajes profundos. Desde este Texto 5, se vislumbran al menos dos alternativas, no excluyentes entre sí: a) que el lector cuente con una construcción de conocimientos que le permita volver a leer el Texto I, unidad física externa, y re(elaborar) muy dinámicamente otros textos, y b) que el lector comunique este conocimiento y lo comparta nuevamente con la misma audiencia o con otras nuevas.

Como se aprecia en esta figura, lo que se intenta captar aquí es el modo en que un lector llega a construir una representación de los significados del texto, por medio de la interacción consigo mismo y con otros lectores u oyentes. También se grafica la posibilidad de que un lector experto evalúe su nivel de comprensión y relea el texto y re-elabore sus significados. En este sentido, solo a través de una enriquecedora puesta en común, por una parte, consigo mismo y, por otra, con otros, el lector estará en condiciones de haber alcanzado una comprensión profunda y plena; al mismo tiempo, también podría decidir si sus opiniones y valoraciones están en un camino congruente con el texto, sus conocimientos previos y sus aprendizajes.

También es posible, y suele acontecer, que el lector no se encuentre inmerso en una comunidad o no quiera buscar esta interacción. En estos casos, la comprensión del texto puede seguir un circuito similar, pero es el lector mismo quien escruta y re-lee sus textos con el fin de cuestionar o interrogar lo leído y su representación mental de los contenidos del texto físico externo. Esta situación se grafica a partir del Lector y el Texto 3, en donde el interlocutor e interrogador es el mismo lector. Esta situación no se aplica solamente a casos cuando el lector se encuentra fuera de contacto con otros lectores, sino que también es factible que ambas situaciones acontezcan simultáneamente. Vale decir, el lector se interroga a sí mismo y entra en transacción con los significados del texto, pero al mismo tiempo o alternativamente también comparte con otros lectores. Evidentemente esta alternativa es la que seguramente enriquece de mejor modo la comprensión profunda del texto leído y genera aprendizajes profundos que permiten aplicaciones y transferencias.

\section{I. Tipos de información y dimensiones en la comprensión}

Junto al Circuito de la Comunicabilidad de lo Leído, de los supuestos centrales y específicos, también se desprende la distinción entre tipos de información 
disponible al lector y ciertas dimensiones en que se procesa tanto la información visual como la no visual. En el siguiente esquema, se busca dar cuenta de:

a. dos dimensiones de lectura (una literal y otra relacional)

b. dos tipos de información textual (superficial e implícita), y

c. dos tipos de procesamiento a partir de la lectura (procesos de memoria y de inferencia)

Por medio de la Figura 2, se busca dar cuenta del macroproceso de la comprensión de textos escritos como una actividad basada en diversas fuentes de información y múltiples dimensiones. Así, la comprensión de un texto se lleva a cabo a partir de tipos de información y procesos muy intrínsecamente vinculados, pero que pueden ser diferenciados metodológicamente. Tanto las flechas de doble punta como las líneas espiraladas representan el modo integrador en paralelo de la construcción de la representación de los significados del texto y la naturaleza interactiva de los procesos a partir de informaciones de diversa índole. Esto quiere decir, por ejemplo, que el lector recurre a sus conocimientos previos, realiza inferencias y se apoya en la información del texto, atendiendo al texto y a sus conocimientos de modo interactivo pero privilegiando a ratos unos u otros.

En la Figura 2 se distinguen dos bloques, en los que se pueden apreciar dos tipos de información y dos dimensiones. Partiendo desde el Texto I, el físico externo, el lector se enfrenta a la información lingüística de superficie (palabras, frases, oraciones, conjuntos de oraciones), cuya característica principal es ser claramente explícita. Esto implica-en un primer momento- leer las letras y representar palabras y frases en la mente del lector. Este carácter de copia literal del texto a la mente del lector hace que a esta dimensión del procesamiento la denominemos 'dimensión literal'. Aunque de menor jerarquía psicolingüística, ella constituye un eje primordial en el andamiaje de la comprensión. A partir de este nivel de información explícita y de esta dimensión literal, se va construyendo progresiva e interactivamente otro tipo de información no explícita con base en los procesamientos de la llamada 'dimensión relacional', es decir, con base en los procesos inferenciales. Ellos permiten al lector construir información no presente en el texto, ya sea por medio de la conexión de información explicita pero no vinculada explícitamente o por medio del aporte de datos fundamentales para el establecimiento de la coherencia local o mesoestructural.

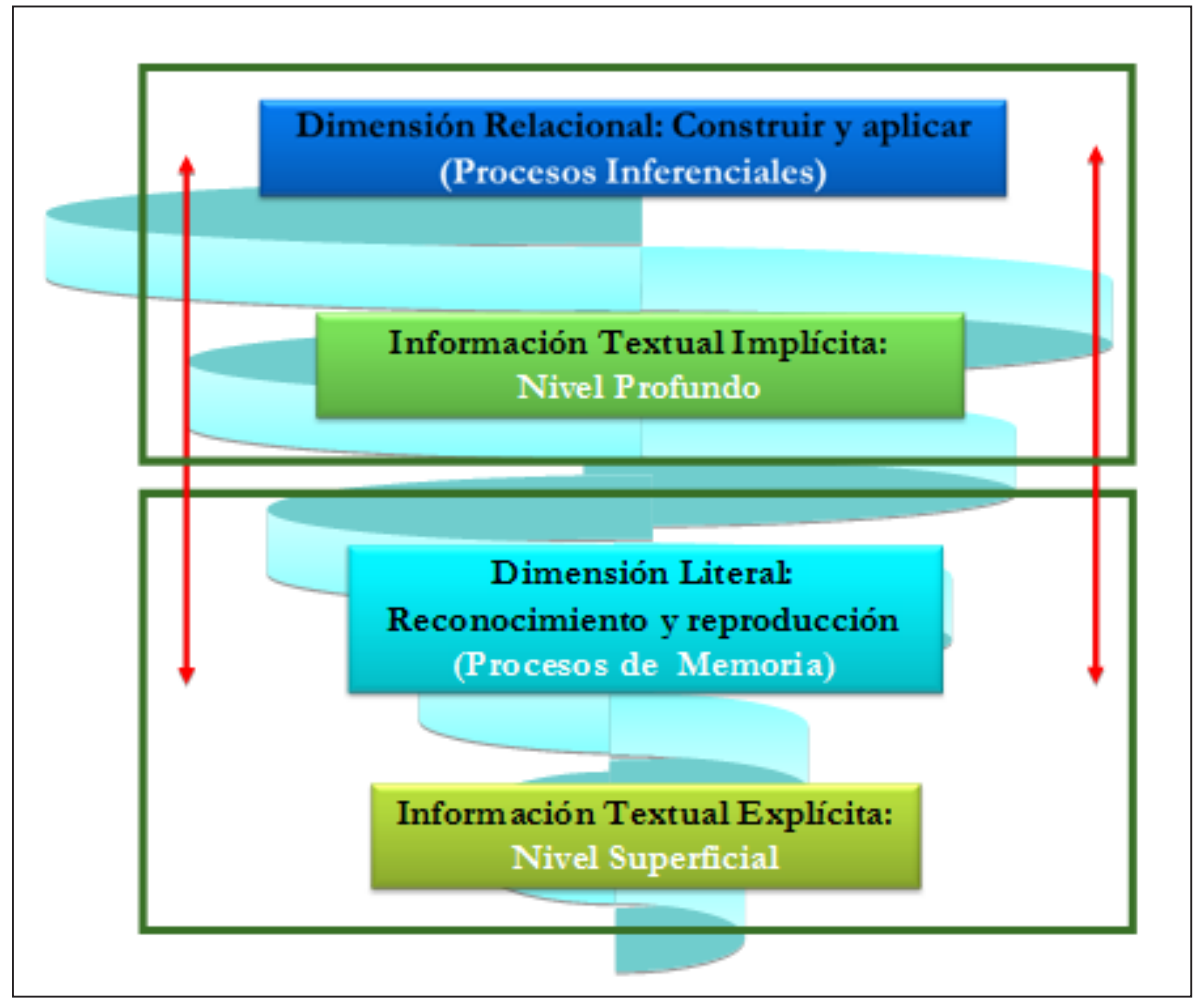

Figura 2. Dimensiones y tipos de información en la lectura. 
Los procesamientos psicolingüísticos subyacentes a los tipos de información y dimensión de este segundo bloque superior conllevan a otro tipo de representaciones menos apegadas al código lingüístico. Así, la dimensión relacional opera sobre información que va más allá de las palabras del texto y se busca construir un significado de lo leído, no una mera representación verbatim del texto. Existe cierto consenso entre los investigadores, aunque con debates en curso, en que la proposición constituiría una alternativa de organizar las representaciones en este siguiente paso, aunque muy seguramente son diversos los formatos en que se va representando el texto en la mente del lector.

Los dos tipos de información que se consignan en el esquema constituyen lo que podríamos llamar: lo visible y lo invisible a los ojos al lector. Esta es la información que está en la superficie del texto y que se relaciona con la dimensión literal y la información que se debe extraer a partir de la superficie (muchas veces no marcada lingüísticamente) y que denominamos implícita y profunda. Esta última no la capta el ojo humano, pero se accede a ella mediante inferencias que -por una parte- se pueden articular a partir de la organización lexicogramatical, esto es, de las palabras, de las tramas de palabras y de los significados que se van elaborando en base a esas palabras y conjuntos de palabras. Esta construcción se va realizando en los sistemas de memoria del sujeto lector, con base en sus conocimientos previos y guiado por los objetivos de lectura. También las inferencias operan a partir de conocimientos previos del lector y de los objetivos de lectura; esto quiere decir que las inferencias no son guiadas únicamente por la información textual, sino que ellas se activan y generan múltiples informaciones, mucha de la cual es olvidada durante el proceso lector y no llega a hacerse parte de la representación final del texto leído.

Ahora bien, con el fin de expandir algunas de estas ideas y de profundizar en estos aspectos de nuestra propuesta, en la Figura 3 (similar a la anterior en formato) precisamos algo más acerca de las relaciones entre comprensión de textos, estrategias de lectura y aprendizaje.

Tal como decíamos más arriba, la comprensión profunda de un texto, entonces, exige como requisito esencial que el lector sea capaz de procesar información en las dos dimensiones (literal y relacional), pero -sobre todo- que también disponga de un conjunto de estrategias que -en términos ideales- le permitan al lector alcanzar, desde la óptica de la TC, el principio fundamental de la comprensión: la acreditabilidad de lo comprendido. Esto implica -en un sentido extremo- no solo comprender el

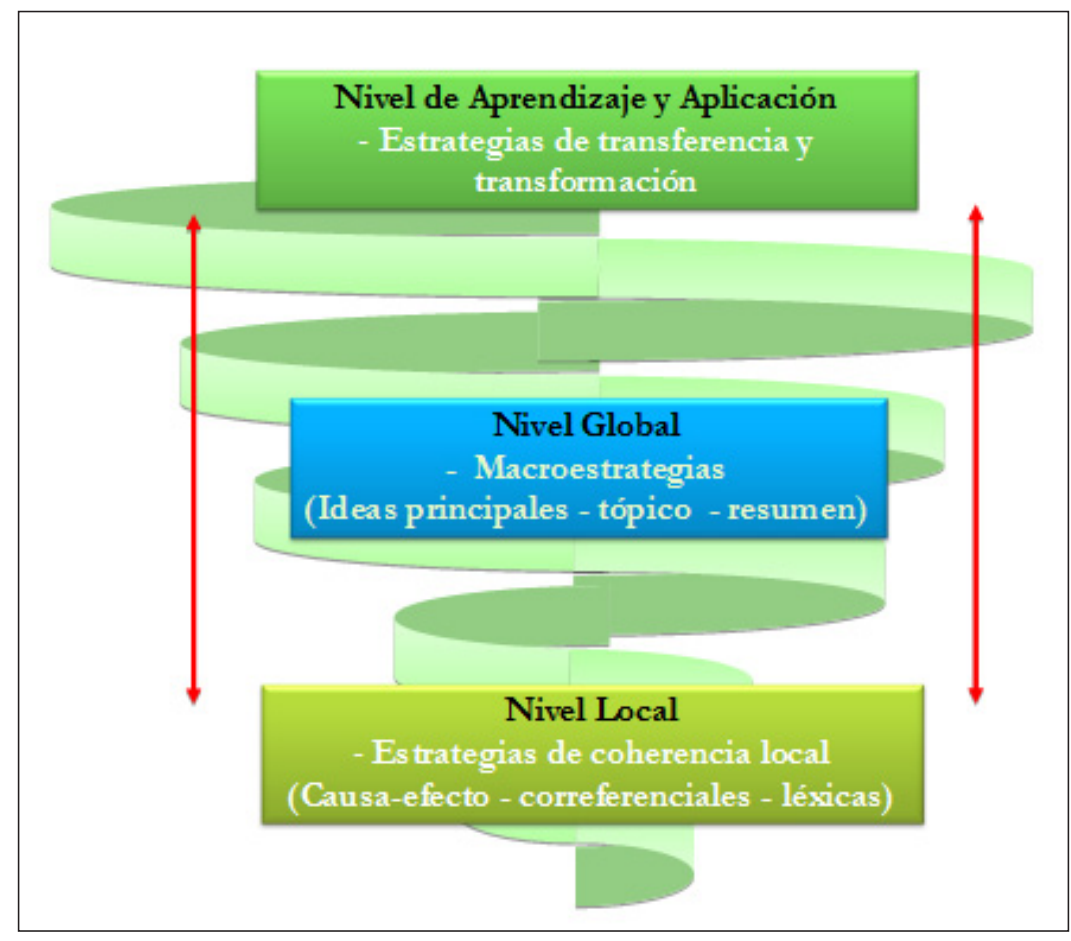

Figura 3. Niveles de la lectura y estrategias implicadas. 
texto en sentido profundo, sino también buscar aprender a partir del mismo; para ello, se requiere de un amplio y variado bagaje de estrategias que no tan solo le ayuden al lector a realizar procesos de lectura a nivel de palabras y oraciones, sino que también lo conduzcan a elaborar las ideas principales y a conectarlas coherentemente (macroestrategias) y a alcanzar aprendizajes de calidad (estrategias de transferencia, transformación y aplicación a nuevos contextos).

Ahora bien, tal como se grafica en la Figura 3, cuando logramos llegar a un nivel de aplicación de lo leído y de transferencia de conocimientos a situaciones nuevas, se alcanzan niveles de aprendizaje significativos y se construyen conocimientos relativamente estables en el tiempo. Estos conocimientos, elaborados a través de procesos de comprensión y aprendizaje serán sustento de posteriores conocimientos encadenados. Como se puede desprender de lo hasta aquí señalado, esta concepción de comprender un texto en sentido profundo se acerca mucho a la idea de aprender del texto. La línea divisoria entre ambos conceptos es difusa, aunque el aprendizaje a partir del texto se vincula preferentemente con la habilidad de emplear la información extraída del texto, por medio de estrategias de transferencia y aplicación a situaciones nuevas. No obstante ello, aprender a partir del texto también se aplica a niveles elementales como recordar y reproducir información del texto, si bien sería un nivel muy bajo en la jerarquía de aprendizajes posibles. En suma, lo característico del aprendizaje es la aplicación de la información textual a contextos nuevos.

\subsection{El comprendedor y el Entorno de la Actividad de Lectura en el marco de la TC}

La noción de objetivos de lectura no ha estado exenta de diversidad $y$ ha ido incorporándose paulatinamente en los modelos de comprensión del discurso. En particular, ello ha ocurrido a medida que se ha ido indagando en el modo de estimular o mejorar la comprensión y el aprendizaje de los contenidos textuales y de aportar a la construcción de un lector activo y crítico.

Como se sabe, la cuestión de los objetivos o propósitos de lectura por parte del lector ha sido abordada desde una multiplicidad de enfoques y escenarios $y$, en algunos casos, estableciendo leves distinciones terminológicas y conceptuales. Por ejemplo, se ha estudiado lo que algunos denominan la perspectiva del lector (Ramsay \& Sperling, 20 I0); otros han abordado la influencia de las tareas de lectura (Guthrie, Wingfield, Humenick, Perencevich, Taboada \& Barbosa, 2006); algunos investigadores se han interesado en los propósitos del lector (Schraw \& Dennison, 1994); paralelamente se ha emprendido investigación en las instrucciones dadas al lector (Schaffner \& Schiefele, 2007; McCrudden, Magliano \& Schraw, 20l0); $y$, también, se han desarrollado estudios a partir de preguntas directivas (King, 1989; Graesser, Gordon \& Brainerd, 1992; Graesser \& Lehman, en prensa). La mayoría de estas indagaciones buscan estudiar lo que -en términos generales- se denomina 'interés', ya sea situacional o personal (Schraw \& Lehman, 200I; Schraw, Flowerday \& Lehman, 200I; McCrudden \& Schraw, 2006) o, de modo más general, lo que también nombran como 'motivación'.

Ahora bien, en el marco de nuestra propuesta, tal como lo declaramos en los supuestos específicos de la TC, distinguimos entre objetivos funcionales y objetivos del lector (Parodi et al., 20l0). Los primeros se definen como externos al lector $y$ normalmente intentan guiar, motivar, dirigir o introducir un objetivo en su lectura; claramente no emergen del lector mismo sino de su contexto institucional (de trabajo o laboral, educativo, o de un ámbito de investigación), pero pueden llegar a ser asumidos comprometidamente como propios del lector. También es factible que en algunos entornos de lectura no exista ningún objetivo funcional, vale decir, no necesariamente cada vez que un lector enfrenta un texto escrito se establece o determina una tarea específica de naturaleza externa, dado que el lector puede leer en entornos no formales y solo por divertimento o interés personal. Esto quiere decir que el lector puede, en ocasiones, leer únicamente guiado por objetivos personales y no enmarcados en un contexto que defina su tarea de lectura, aunque se encuentre inserto en un contexto institucional.

Por su parte, los objetivos del lector son internos y propios de cada lector y pueden no coincidir con los funcionales. Es muy factible que en muchas oportunidades los lectores puedan no estar plenamente conscientes de qué buscan o qué guía su lectura, pero normalmente suele existir uno 0 varios objetivos ya sean establecidos previamente o durante la lectura. Esto es una cuestión más bien de grado de conciencia respecto de los objetivos. No obstante ello, la toma de conciencia de los objetivos 
es justamente parte de otro de los supuestos específicos de la TC, como lo es el desarrollo de la conciencia y el control del proceso de lectura. Mediante el establecimiento consciente de los objetivos de lectura del lector y del reconocimiento de los eventuales objetivos funcionales, el proceso de comprensión adquiere mayor rigurosidad y el lector es consciente de sus compromisos y responsabilidades $y$, según ello, podrá evaluar, controlar y monitorear su lectura. Es indispensable que un lector tenga algún grado de conciencia de si está leyendo con el fin de entretenerse y pasar el tiempo porque, por ejemplo, viaja en un bus $y$ solo busca acortar el tiempo del viaje, o si está preparando un examen para optar a un grado académico.

La Figura 4 (adaptada de una propuesta inicial, publicada en Parodi et al., 20I0) muestra el modo en que concebimos la interacción entre los dos tipos de objetivos ya distinguidos, las estrategias de lectura y los géneros del discurso, todo ello en el marco de un contexto cultural y social específico.

Una cuestión muy interesante en el ámbito de la investigación la constituye el modo en que se puede alcanzar un equilibrio entre los objetivos del lector (propiamente tales) y los objetivos funcionales. Está claro que si ambos no coinciden y no logran alinearse, el resultado del proceso de comprensión puede ser muy diverso en relación a la situación contextual en que se encuentre inmerso el lector. Esto es, si -por ejemplo- un determinado lector enfrenta un texto como tarea de evaluación para ingresar a una cierta institución y sus objetivos personales no se ajustan con los identificados desde el medio externo, puede ser que el resultado de la evaluación no sea el esperado en términos institucionales. Esto es que el proceso de construcción de la representación a que arribe el lector esté orientado por objetivos que no buscan ir en el mismo camino de los significados construidos a partir del texto que se espera institucionalmente. Cómo ajustar y lograr un equilibrio transaccional entre estos dos tipos de objetivos es algo relevante en términos tanto teóricos como aplicados.

Tanto las estrategias de lectura como los géneros discursivos están en directa relación con los objetivos, pues dependiendo del género que se lea muy probablemente se generarán objetivos específicos (funcionales y del lector) y se pondrán en ejecución estrategias particulares. Ciertamente, no es lo mismo leer un artículo de investigación de biotecnología para escribir luego una reseña a propósito de este, que leer una novela policíaca durante unas vacaciones de verano para pasar la tarde de descanso.

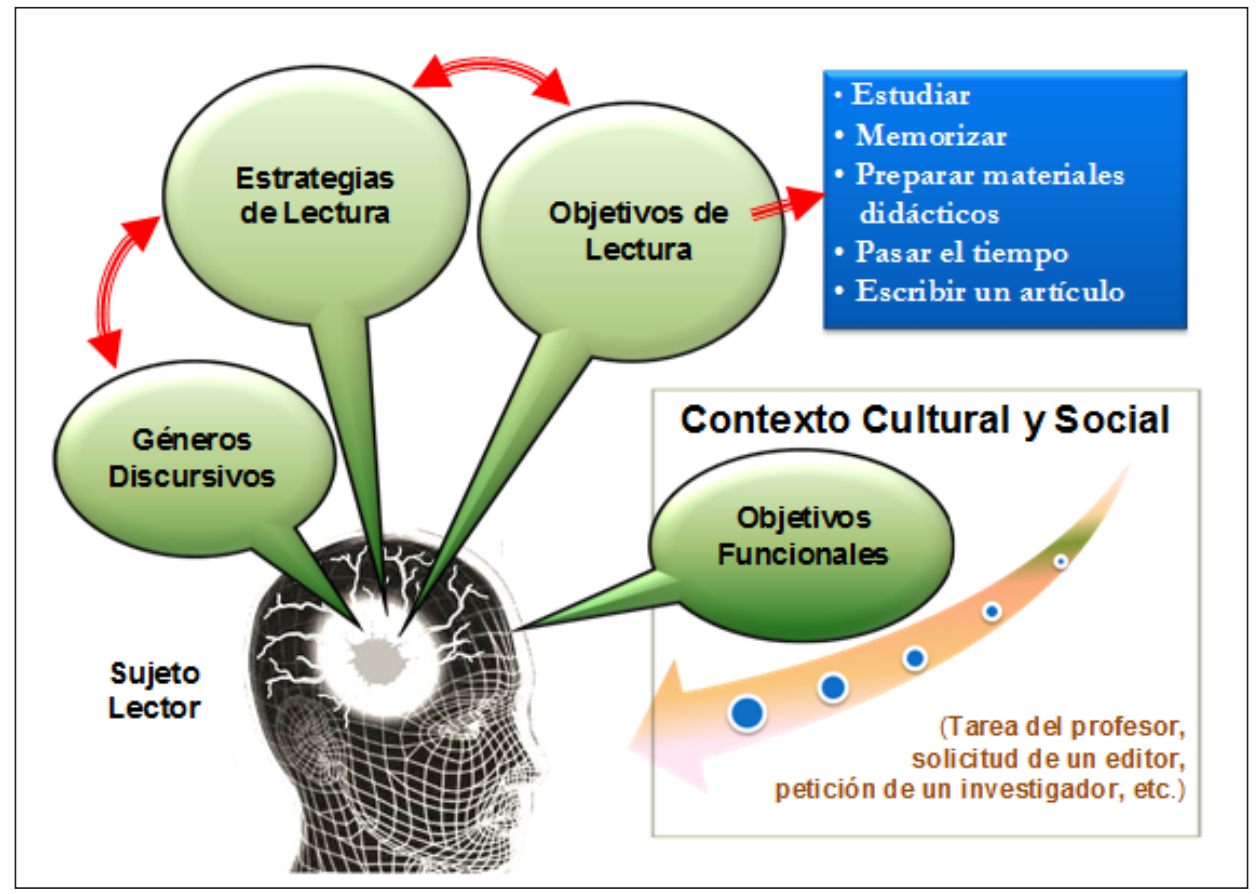

Figura 4. El entorno de la lectura. 
3.3. Desde la perspectiva de la TC: ¿Exigen los textos diversos tipos de inferencias a los lectores, según género discursivo y especialidad?

La investigación en torno a las inferencias como procesos fundamentales en la comprensión de textos escritos ha avanzado de modo sustantivo en los últimos veinte años (MacKoon \& Ratcliff, 1992; Graesser, Singer \& Trabasso, 1994: MacKoon \& Ratcliff, 1998; Zwan \& Radvansky, 1998; León \& Pérez, 2002; Parodi, 2003, 2005, 2007a, 2007b; Cook \& Guéraud, 2005; Ibáñez, 2007a, 2007b, 2008; Ratcliff \& MacKoon, 2008). Más recientemente, el foco de las investigaciones ha variado progresivamente al prestar mayor atención a los diversos géneros discursivos y las temáticas de lectura, y se han superado etapas previas en que se debatía por determinar los tipos mínimos y máximos de inferencias que se realizaban, basados en criterios de tiempos de lectura. En la actualidad, las dos posturas más destacadas en cuanto a inferencias en el ámbito de la comprensión de textos escritos son la perspectiva del procesamiento basado en la memoria (MacKoon \& Ratcliff, 1998; Ratcliff \& MacKoon, 2008) y la perspectiva basada en la explicación (Graesser et al., 1994; Zwan \& Radvansky, 1998). Aunque ambas posturas pueden aparecer en conflicto y contrapuestas, en general hoy en día se tiende a una visión más integradora y de conjunto.

Ahora bien, desde los supuestos de la TC, la investigación acerca de las inferencias reviste un foco altamente relevante en el estudio de la comprensión, tal como se establece en uno de sus supuestos específicos. Desde este escenario, se hace necesario avanzar en el estudio de los procesos inferenciales que caractericen a textos pertenecientes a géneros disciplinares que circulan en contextos de especialidad, pues el estudio descriptivo de estos textos ha revelado rasgos distintivos y diferenciadores a través de algunas disciplinas científicas (Parodi, 20l0b). A partir de estos hallazgos empíricos diferenciales en las relaciones semánticas presentes en textos disciplinares es factible postular que comprender uno u otro texto especializado no necesariamente requiere los mismos procesos inferenciales y muy posiblemente tampoco las mismas estrategias. En este sentido, el estudio de la comprensión de textos en una perspectiva contemporánea se une a la investigación desde la lingüística de corpus (Parodi, 20 I0c) y se proyecta desde una perspectiva 'guiada por el corpus' e 'informada a partir de los géneros de especialidad'. En parte, debido a que existe también mayor conciencia entre los investigadores de que la sola descripción de los textos por sí mismos constituye una sola fuente de información, se hace necesario buscar una complementariedad en que se cuente con información concurrente, en este caso, acerca del procesamiento psicolingüístico. Esta vía de trabajo interdisciplinario y convergente entre descripción y estudio del procesamiento de las mismas unidades y constructos teóricos se presenta como un camino necesario (Parodi, 2007a, 2007b, 20I0c; Gries, 2010). Aunque, Gries (2010: 333) propone que la lingüística de corpus debería ser "a psycholinguistically informed, (cognitively inspired) usage-based linguistics", nuestra postura se articula justamente en el sentido contrario. Otros investigadores argumentan que la lingüística de corpus y la lingüística cognitiva son paradigmas irreconciliables, dado que estos autores optan por una postura radical desde una perspectiva social del lenguaje y declaran que no existe preocupación por los aspectos psicológicos del mismo (Teubert, 2005).

Como un modo de aproximarnos a los procesos inferenciales y a las diferencias a través de textos de géneros diversos y de demostrar que la complementariedad (entre lingüística de corpus y psicolingüística) es un requisito irrevocable, presentamos los siguientes dos textos, como se ve en la Tabla 2.

Como se puede apreciar en estos dos textos, uno de ellos exige al lector realizar abundantes inferencias correferenciales de tipo pronominal, caso típico de un relato, donde predomina la trama narrativa. Junto a ello, se requiere establecer conexiones espaciales y temporales fundamentales para la construcción de una representación coherente de las ideas de este texto. Resulta así esencial la dimensión de los personajes y de la espacialidad. Claramente, el foco está en las personas y las referencias son -en la mayoría de los casos- personales y -en menor grado- locativas o temporales. No existen relaciones condicionales. En el otro texto, con el fin de mantener el hilo de lo que se dice, el lector debe realizar inferencias de sustitución léxica a parir de complejos grupos nominales en donde las nominalizaciones de tipo proceso y objeto son abundantes. Al mismo tiempo, el lector debe ser capaz de establecer diversos nexos relacionales de tipo causal y condicional. En este segundo texto no existen personajes humanos ni animados y las referencias son a objetos y procesos. A diferencia 
Tabla 2. Textos de naturaleza divergente en cuanto a sus inferencias.

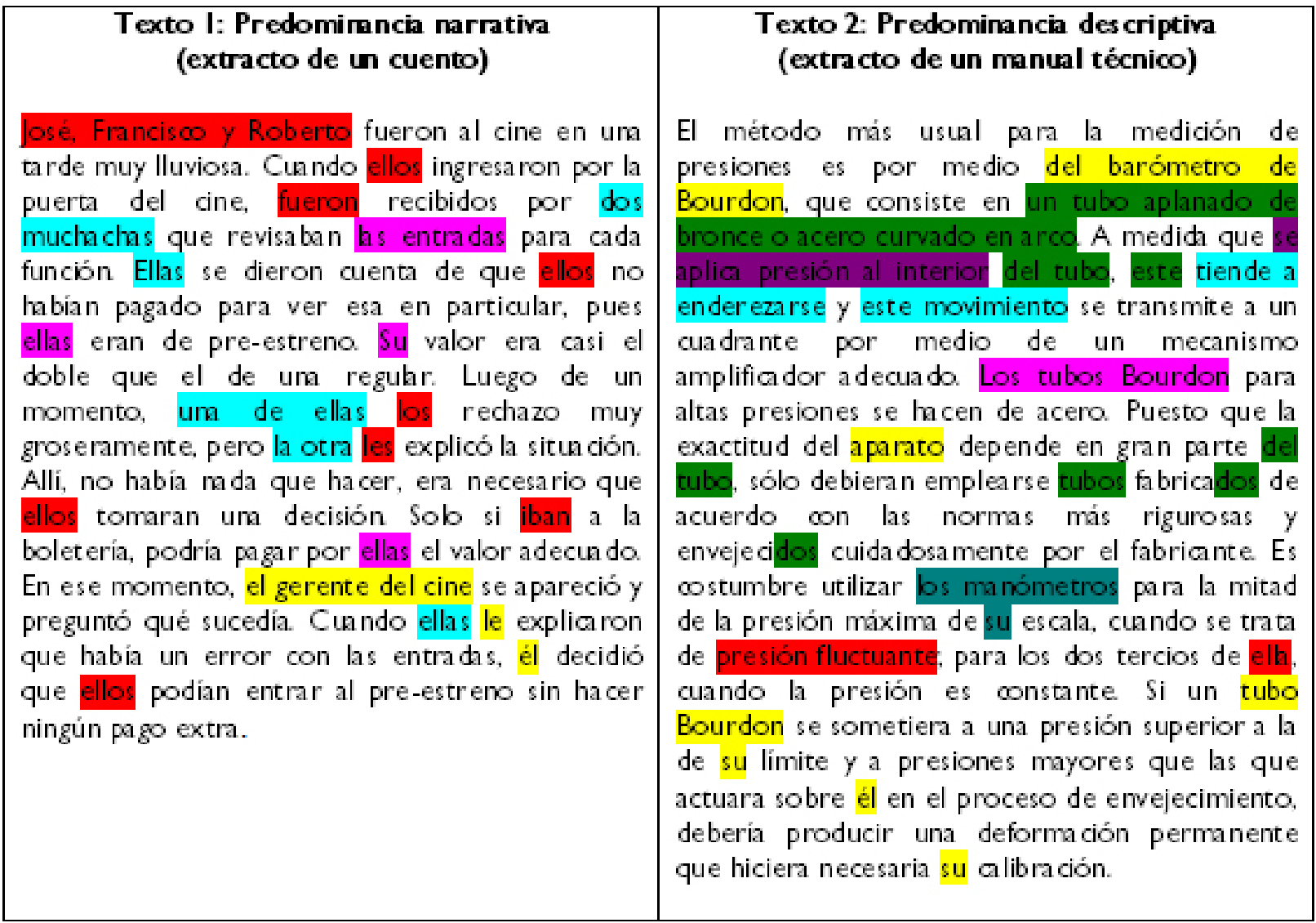

del primer texto, en el técnico descriptivo priman las relaciones condicionales y de causalidad. También se observan relaciones correferenciales similares a las del primer texto, pero se articulan a partir de referentes diferentes; no son seres humanos.

Un breve análisis de estos dos ejemplos nos permite postular posibles diferencias reveladoras que el procesamiento psicolingüístico de uno y otro texto podría imponer a un determinado lector. Al mismo tiempo, ponen de relieve que muchas de las inferencias a realizar serían de naturaleza divergente y muy posiblemente los objetivos de lectura también podrían variar en ciertos contextos. Por ello, enseñar a comprender uno y otro texto y evaluar la comprensión de uno y otro demanda atención a precisiones conceptuales diferentes, relaciones semánticas diferentes, tipos de procesamientos particulares, y conocimientos específicos y tareas diversas. Esto quiere decir, en términos más precisos, que las estrategias de comprensión están determinadas por los géneros discursivos, las tramas textuales, los contenidos específicos, las marcas textuales explícitas e implícitas y los tipos de procesos e inferencias que cada texto exija al lector.

Lo dicho hasta aquí ha enfatizado una perspectiva eminentemente verbal del procesamiento psicolingüístico. De hecho, la comparación entre los dos textos presentados más arriba se basa en criterios exclusivamente lingüísticos a partir de relaciones marcadas en la superficie textual. Sin embargo, la naturaleza del texto escrito es de hecho mucho más compleja y se hace necesario abordarlo desde todas sus dimensiones. Desde la TC, tal como comentamos en el próximo apartado, buscamos aproximarnos al texto de modo más integral.

\subsection{La comprensión de textos escritos multisemióticos en el marco de la TC}

A partir de lo dicho más arriba, una aproximación más integral, debe -en efecto- contemplar los diversos sistemas semióticos presentes en los textos según la disciplina, tal como se indica en el supuesto de la TC: 'Búsqueda de Coherencia'. No 
obstante ello, es evidente que la investigación en comprensión de textos escritos se ha centrado en su concepción eminentemente verbal y se han abordado muy recientemente otros sistemas semióticos, también co-constructores del texto escrito. En este contexto, Parodi (20lOb) propone cuatro sistemas semióticos constitutivos del texto escrito estático, como muestra la Figura 5.

Basado en esta distinción cuatripartita, Parodi (20I0b), junto a Carvallo (20I0), Aravena (20I0), Aguilera (20I0) y Santana (20I0), establecen empíricamente, a partir del estudio de un corpus en seis disciplinas, una primera aproximación descriptiva de los rasgos multisemióticos de un conjunto de textos, basada en corpus disciplinares. Desde este marco, Parodi (20lOb) propone distinguir dos polos extremos de un continuum en que se tenderían a ubicar, según el tipo y cantidad de artefactos multisemióticos en el Corpus PUCV-20I0, por un lado, los textos de Historia y, por otro, los de Física. Mientras los primeros son predominante verbales y presentan escasos rasgos de los sistemas gráficos y matemáticos, los de física pueden llegar a tener un promedio de seis artefactos multisemióticos por página, tales como fórmulas, gráficos, tablas y esquemas. Así, los datos empíricos aportados en dicha investigación ponen de relieve la naturaleza diferencial de la constitución textual de los géneros discursivos a través del estudio de seis disciplinas de las Ciencias Sociales y Humanidades (Historia,

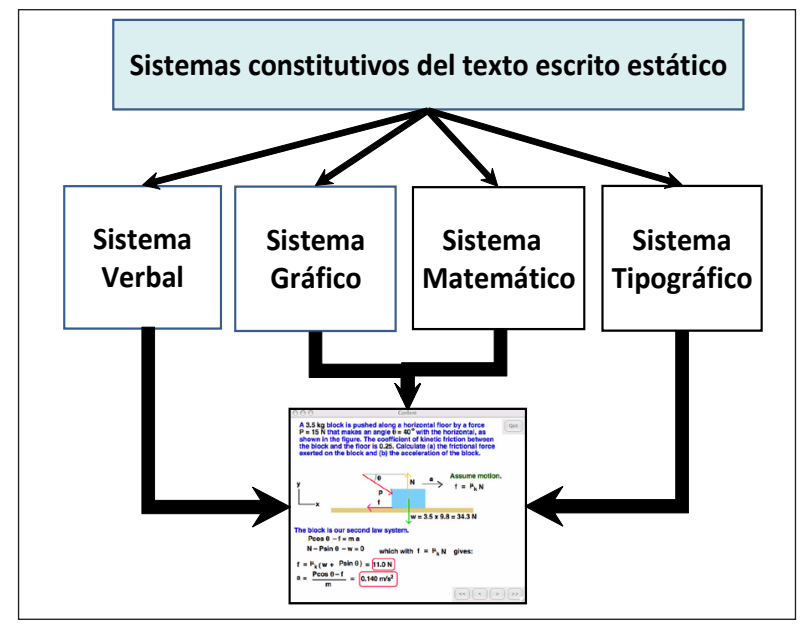

Figura 5. Cuatro sistemas semióticos constitutivos del texto escrito estático.
Literatura y Lingüística) y de las Ciencias Básicas (Biotecnología, Química y Física). Ello se ve reflejado en la siguiente Figura 6.

Tal como indica Parodi (20l0b), nuestra mirada analítica de los textos escritos ya no solo debe apuntar exclusivamente al sistema verbal sino también a la intersemiosis entre los diversos sistemas semióticos constitutivos de un texto escrito estático. Así, debemos avanzar desde el estudio de la descripción textual y las múltiples relaciones semánticas allí existentes hasta la investigación del procesamiento psicolingüístico a partir de textos que se construyen en base a diversos sistemas semióticos. Ello implica estudiar la interacción entre información de diversa índole e investigar cómo se construye la coherencia discursiva ya no tan solo guiada por relaciones semánticas de tipo verbal (sean marcadas o no marcadas lingüísticamente), sino que provenientes de múltiples otros sistemas semióticos y que exigen representaciones diversas.

Ahora bien, como se sabe, el desarrollo de teorías y modelos de comprensión ha estado fuertemente centrado en el procesamiento del texto estático de naturaleza eminentemente verbal. Es relativamente sencillo imaginar una razón plausible: los desafíos tremendos que esto ha impuesto, pues a pesar de los inmensos avances, aún contamos con un panorama muy parcial y las incógnitas por explorar no resultan de ningún modo menores. No obstante

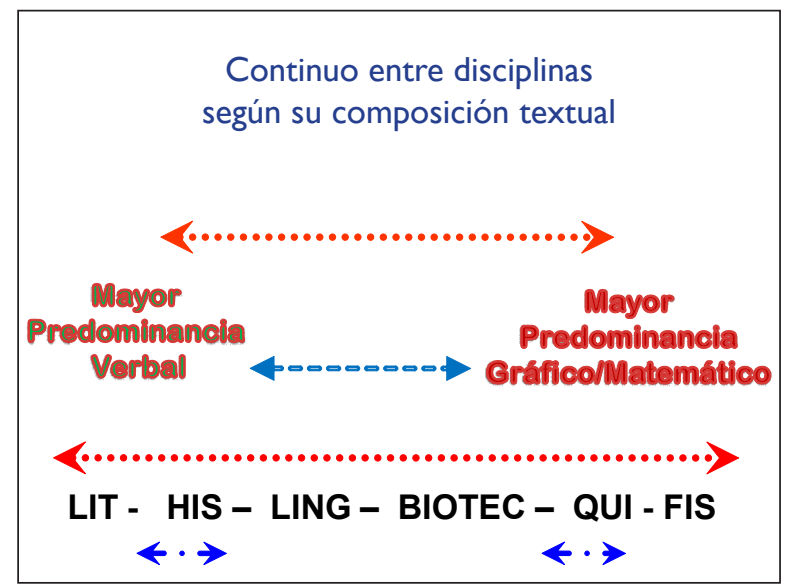

Figura 6. Continuum de disciplinas según constitución textual. 
ello, las propuestas de Sadoski (1992, 2009), Sadoski y Paivio (200I, 2007), Schontz (2002), Schnotz, Bannert y Seufert (2002), Schnotz y Bannert (2003), entre otros, buscan adentrarse en un terreno imprescindible. Ciertamente estas indagaciones son aún extremadamente preliminares y una mirada profunda y crítica revela que ellas no logran capturar de modo integral la multidimensionalidad del fenómeno del cual buscan dar cuenta. En muchos casos se detecta un gran interés por los textos dinámicos (cine, video clips, Internet en sentido amplio, etc.) más que por los estáticos (libros, artículos y documentos en formato papel o digital, pero de modo lineal no-interactivo); sin embargo, mientras no se avance en describir el texto escrito estático, es evidente que más difícil aún resulta la indagación de los multimedia interactivos. Queda así abierto un terreno fecundo a la exploración en que, tal como apuntamos anteriormente, la complementariedad entre lingüística de corpus y psicolingüística es evidentemente un requisito sine qua non. Solo una psicolingüística debidamente informada en base a corpus disciplinares, géneros discursivos específicos y artefactos multisemióticos podrá indagar procesamientos de textos ecológicos y efectivamente situados.

\section{Comentarios finales}

A lo largo de este artículo hemos profundizado y expandido el marco conceptual de la denominada Teoría de la Comunicabilidad. La hemos nominado así, por primera vez, con el afán de operacionalizar una propuesta teórica que ya hace varios años se viene construyendo dentro de la Escuela Lingüística de Valparaíso. Al delinear más pormenorizadamente nuestra propuesta, hemos definido y comentado un principio fundamental y diez supuestos específicos. Todos ellos, separados metodológicamente para su presentación, operan -en muchos casos- de modo muy interrelacionado y se superponen y conectan de modo particular. Todos ellos, en su conjunto, buscan presentar nuestra visión de la comprensión de textos escritos como un macroproceso multidimensional en cuyo núcleo convergen diversos tipos de información, de relaciones y de procesos y subprocesos. También hemos detallado elementos relevantes en el procesamiento del texto escrito como es cierto tipo de información explícita y otra implícita y hemos distinguido entre una dimensión literal y otra relacional, las cuales operan en paralelo e interactivamente.

Especial énfasis hemos puesto en destacar los procesos semánticos divergentes que subyacen en textos de diversa naturaleza y que exigen inferencias de tipo diferencial al lector de unos y otros textos de géneros diversos. Del mismo modo, hemos destacado las relaciones semánticas ya no solo apoyadas en marcas lingüísticas, presentes en el texto escrito, sino que hemos llamado la atención al procesamiento multisemiótico de los textos y a las relaciones tanto intra como intersemióticas entre al menos- los sistemas verbal, gráfico, matemático y tipográfico. Asimismo, hemos destacado la necesidad de atender a los procesos de comprensión de estos textos y sus rasgos multisemióticos, avanzando y superando la excesiva concentración en lo eminentemente verbal.

Una de las proyecciones, que desde estos antecedentes se vislumbra, es una línea de trabajo e investigación que dice relación con un programa que proponemos se denomine 'Leer A través de las Disciplinas' (LAD). Este programa podría articularse a través de corpus electrónicos que contengan textos ejemplares pertenecientes a géneros identificados a través de un grupo de disciplinas y a través de un conjunto de guías metodológicas para el desarrollo de estrategias de comprensión de textos escritos, en español como lengua materna o en inglés como lengua extranjera o -en algunos casos- en ambas al mismo tiempo. Junto a lo anterior, un componente de este programa podría organizarse a partir de lo que hoy se entiende como corpus de aprendientes (learner corpora) y la idea de un "aprendizaje guiado por el corpus" (Data-driven learning: DDL); desde el cual los alumnos interactúan con los corpus y actúan como investigadores a través de los mismos. Dejamos así abierta una serie de posibilidades para avanzar, desde el marco de la TC, hacia el desarrollo de estrategias de comprensión en géneros diversos y a través de las disciplinas. 


\section{REFERENCIAS BIBLIOGRÁFICAS}

Aguilera, C. (2010). La identificación de los géneros discursivos en el sub-corpus de Química del Corpus Académico PUCV-2010: Hacia una propuesta metodológica integrada. Tesis para optar al grado de Licenciado en Lengua y Literatura Hispánica, Pontificia Universidad Católica de Valparaíso, Chile.

Aravena, C. (20I0). Artefactos visuales en textos académicos de Historia y Literatura a nivel de doctorado. Tesis para optar al grado de Magíster en Lingüística Aplicada, Pontificia Universidad Católica de Valparaíso, Chile.

Carvallo,W. (20I0). El Modo visual gráfico y el verbal de un Género académico en el sub-corpus de Química correspondiente al corpus PUCV 2010. Tesis para optar al grado de Licenciado en Lengua y Literatura Hispánica, Pontificia Universidad Católica de Valparaíso, Chile.

Cook, A. \& Guéraud, S. (2005). What have we been missing? The role of general world knowledge in discourse processing. Discourse Processes, 39(2\&3), 265-278.

Damasio, A. (2006). En busca de Espinosa: Neurobiología de la emoción y de los sentimientos. Barcelona: Drakontos.

Damasio, A. (20I0). Self comes to mind. Constructing the conscious brain. New York: Pantheon Books.

Graesser, A. (2007). An introduction to strategic reading comprehension. En D. McNamara (Ed.), Reading comprehension strategies:Theories, interventions and technologies (pp. 3-26). Mahwah, NJ: Erlbaum.

Graesser, A., Gordon, S. \& Brainerd, L. (1992). QUEST: A model of question answering. Computers and Mathematics with Applications, 23, 733-745.

Graesser, A., Singer, M. \& Trabasso, T. (1994). Constructing inferences during narrative text comprehension. Psychological Review, I0 I, 37I-395.

Graesser,A. \& Lehman, B. (en prensa). Questions drive comprehension of text and multimedia. En M.T. McCrudden, J. Magliano \& G. Schraw (Eds.), Text relevance and learning from text. Greenwich, CT: Information Age Publishing.

Gries, S. (2010). Corpus linguistic and theoretical linguistic: A love-hate relationship? Not Necessarily. International Journal of Corpus Linguistics, I5(3), 327-343.

Guthrie, J., Wigfield, A., Humenick, N., Perencevich, K., Taboada, A. \& Barbosa, P. (2006). Influences of stimulating tasks on reading motivation and comprehension. The Journal of Educational Research, 99(4), 232-245.

Ibáñez, R. (2007a). Cognición y comprensión: Una aproximación histórica y crítica al trabajo investigativo de Rolf Zwaan. Revista Signos. Estudios de Lingüística, 40(63), 8I-I00.

Ibáñez, R. (2007b). Comprensión de textos disciplinares escritos en inglés. Revista de Lingüística Teórica y Aplicada (RLA), 45(I), 67-85.

Ibáñez, R. (2008). Comprensión de textos académicos escritos en inglés: Relación entre nivel de logro y variables involucradas. Revista Signos. Estudios de Lingüística, 4 I (67), 203-229.

King, A. (1989). Effects of self-questioning training on college students' comprehension of lectures. Contemporany Educational Psychology, I4, 366-38I.

Kintsch,W. (1998). Comprehension:A paradigm for cognition. Cambridge: Cambridge University Press.

Koch, C. (2004). The quest for consciousness, a neurobiological approach. Englewood, Colorado: Roberts \& Company Publishers. 
León, J. \& Pérez, O. (2002).Taxonomías y tipos de inferencias. En J. León (Coord.), Conocimiento y discurso. Claves para inferir y comprender (pp. 45-65). Madrid: Pirámide.

McCrudden, M. \& Schraw, G. (2006). Relevance and goal-focusing in text processing. Educational psychology review, 19(2), II3-I39.

McCrudden, M., Magliano, J. \& Schraw, G. (20I0). Exploring how relevance instructions affect personal reading intentions, reading goals and text processing: A mixed methods study. Contemporany Educational Psychology, 35(4), 229-24I.

McKoon, G. \& Ratcliff, R. (1992). Inference during reading. Psychological Review, 99, 440-446.

McKoon, G. \& Ratcliff, R. (1998). Memory based language processing: Psycholinguistic research in the 1990's. Annual Review of Psychology, 49, 25-42.

McKoon, G. \& Ratcliff, R. (2008). Meanings, propositions, and verbs. Psychonomic Bulletin and Review, 15, 592-597.

McNamara, D. \& Magliano, J. (2009). Toward a Comprehensive Model of Comprehension. En B. Ross (Ed.), The Psychology of learning and motivation:Advances in research and theory (pp. 297-372). Illinois:Academic Press.

Paivio, A. (1986). Mental representation: A dual coding approach. New York: Oxford University Press.

Paivio,A. (2007). Mind and its evolution:A dual coding theoretical approach. Mahwah, NJ: Erlbaum.

Parodi, G. (1992). Estructura textual y estrategias lectoras. Revista Lenguas Modernas, 19, 89-98.

Parodi, G. (1993). Macroestrategias en la comprensión de textos escritos: Relaciones retóricas implícitas. Revista Estudios Filológicos, 28, 75-86.

Parodi, G. (2003). Relaciones entre lectura y escritura: Una perspectiva cognitiva discursiva. Antecedentes teóricos y resultados empíricos. Valparaíso: EUV.

Parodi, G. (2005). Comprensión de textos escritos. Buenos Aires: EUDEBA.

Parodi, G. (2007a). Comprensión y aprendizaje a partir del discurso especializado escrito: Teoría y empírica. En G. Parodi (Ed.), Lingüística de corpus y discursos especializados: Puntos de mira (pp. 223-258). Valparaíso: EUV.

Parodi, G. (2007b). Reading-writing connections: Discourse-oriented research. Reading and writing:An Interdisciplinary Journal, 20(3), 225-250.

Parodi, G. (2010a). "Comprensión de textos escritos ¿Cómo hemos avanzado desde la teoría a la evaluación?”. Conferencia Plenaria Inaugural, Congreso Cátedra UNESCO para la Lectura y la escritura, con motivo de la Inauguración de la SubSede en la Universidad General Sarmiento, Buenos Aires, Argentina.

Parodi, G. (20l0b). Multisemiosis y lingüística de corpus: Artefactos (multi)semióticos en los textos de seis disciplinas en el corpus PUCV-20 I0. Revista de Lingüística Teórica y Aplicada (RLA), 48(2), 33-70.

Parodi, G.(20I la). “Alfabetización académica basada en corpus, géneros y disciplinas:La comprensión del Discurso Especializado". Conferencia Plenaria con motivo de la Inauguración de la SubSede de la Cátedra de la Cátedra UNESCO Lectura y Escritura Chile, en la Universidad de Antofagasta, Antofagasta, Chile.

Parodi, G. (20I Ib). "How may teachers capitalize from specialized corpora to help students develop reading comprehension strategies?: The case of undergraduate and PhD learners across disciplines in Chile". Panel Plenario en el XIX Congreso Internacional de la Asociación Española de Lingüística Aplicada (AESLA). Universidad de Salamanca, Salamanca, España. 
Parodi, G., Peronard, M. \& Ibáñez, R. (20I0). Saber leer. Madrid:Aguilar.

Penrose, R. (1996). Las sombras de la mente. Hacia una comprensión científica de la consciencia. Barcelona: Crítica.

Peronard, M. (2005). La metacognición como herramienta didáctica. Revista Signos. Estudios de Lingüística, 75(38), 6I-74.

Peronard, M. \& Gómez, L. (1985). Reflexiones acerca de la comprensión lingüística: Hacia un modelo. Revista de Lingüística Teórica y Aplicada (RLA), 23, I 9-32.

Peronard, M., Gómez, L., Parodi, G. \& Núñez, P. (1998). Comprensión de textos escritos: De la teoría a la sala de clases. Santiago: Editorial Andrés Bello.

Peronard, M., Velásquez, M., Crespo, N. \& Viramonte, M. (2002). Conocimiento metacognitivo del lenguaje escrito: Instrumento de medición y fundamentación teórica. Revista Infancia y Aprendizaje, 25(2), I $3 \mid$ - I 45.

Ramsay, C. \& Sperling, R. (2010). Designating reader perspective to increase comprehension and interest. Contemporary Educational Psychology, 35(3), 21 5-227.

Ratcliff, R. \& McKoon, G. (2008). Passive parallel automatic minimalist processing. En C. Engel \&W. Singer (Eds.), Better than conscious? Decision making, the human mind, and implications for institutions (PP. 176-189). Cambridge, MA: MIT Press.

Sadoski, M. (1992). Imagination, cognition, and persona. Rhetoric Review, I0, 266-278.

Sadoski, M. (2009). Embodied cognition, discourse, and Dual Coding Theory: New directions. En J. Renkema (Ed.), Discourse, of course: An overview of research in discourse studies (pp. 187-223). Amsterdam: Benjamins.

Sadoski, M. \& Paivio, A. (200I). Imagery and text: A dual coding theory of reading and writing. Mahwah, NJ: Erlbaum.

Sadoski, M. \& Paivio, A. (2007). Toward a unified theory of reading. Scientific Studies of Reading, II, 337-356.

Santana, A. (20l0). Nivel de dominio del inglés, multimodalidad y nivel de comprensión en segunda lengua de textos académicos escritos en inglés: Una aproximación al fenómeno en el ámbito de la Física. Tesis para optar al grado de Magíster en Lingüística Aplicada, Pontificia Universidad Católica de Valparaíso, Chile.

Schaffner, E. \& Schiefele, U. (2007). The effect of experimental manipulation of student motivation on the situational representation of text. Learning and Instruction, I 7(6), 755772.

Scharw, G. \& Dennison, R. (1994). The effect of reader purpose on interest and recall. Journal of Reading Behavior, 26, I-18.

Schraw, G. \& Lehman, S. (200I). Situational interest: A review of the literature and directions for future research. Educational Psychology Review, I3(I), 23-52.

Schraw, G., Flowerday, T. \& Lehman. S. (200I). Increasing situational interest in the classroom. Educational Psychology Review, I3(3), 2 I I-224.

Schnotz, W. (2002). Towards an integrated view of learning from text and visual displays. Educational psychology review, I4(2), I I I-I20.

Schnotz, W., Bannert, W. \& Seufert, T. (2002). Towards an integrative view of text and picture comprehension: Visualization effects on the construction of mental models. En A. Graesser, J. Otero \& J. A. León (Eds.), The psychology of science text comprehension (Pp. 385-4I6). Mahwah, NJ: Erlbaum. 
Schnotz, W. \& Bannert, M. (2003). Construction and interference in learning from multiple representations. Learning and Instruction, 13, 14 I- 156.

Searle, J. (2004). Mind. A brief introduction. Oxford: Oxford University Press.

Sinclair, J. (Ed.) (2004). How to use corpora in language teaching. Amsterdam: Benjamins.

Solms, M. \& Turnbull, O. (2004). El cerebro y el mundo interior. México: Fondo de Cultura Económica.

Teubert, W. (2005). My version of corpus linguistics. International Journal of Corpus Linguistics, IO(I), I-I3.

Zwaan, R.\& Radvansky, G, (1998). Situational models in language comprehension and memory. Psychological Bulletin, I23, 162-185.

* Investigación financiada parcialmente por el Proyecto FONDECYT I090030. 